\title{
La poesía en la vanguardia o la singularidad flamenca de Enrique Morente
}

\author{
Elizabet Fernández Lam-Sen \\ Doctora en Literatura Española
}

\begin{abstract}
Este artículo explora la relación existente entre Enrique Morente y la poesía culta adoptando como referencia su obra musical, la cual abarca casi medio siglo. Gracias a este vínculo tan particular, el artista logró construir su propio concepto de vanguardia sin que se produjese nunca una ruptura con la tradición proveniente. Así indagaremos en lo que supuso para el cantaor términos como "tradición" o "vanguardia", pero siempre atendiendo a su conexión con la poesía culta, lo que significó la apertura de su arte flamenco hacia una trascendencia y una universalización absolutamente distintivas.
\end{abstract}

Palabras clave: Flamenco; poesía; Enrique Morente.

This article explores about the relationship between Enrique Morente and cultured poetry adopting as reference his musical work which spans almost half a century. Thakns to this particular link, the artist was able to construct his own concept of the avant-garde whithout ever breaking with the tradition that came from it. We will explore what terms such as "tradition" or "avant-garde" meant for the flamenco singer, but always taking into account his connection with cultured poetry, which meant the opening of his flamenco art towards an absolutely distinctive trascendence and universalisation.

\section{Introducción}

La singularidad flamenca de Enrique Morente puede concebirse como un alegato hacia la poesía. La construcción de su discografía (1967-2011) se apoya en un universo poético del que participan un total de cuarenta autores, pertenecientes a distintas escuelas líricas, pero que, sin embargo, aparecen vinculados por la admiración que profesaron a la palabra popular. El cantaor nunca romperá con la tradición, pero logrará trascenderla gracias a una lectura personal de la poesía culta, la cual le ayuda a trazar las coordenadas de su vanguardismo que se revela como un proceso abierto de metamorfosis. Así la lógica de la creación morentiana se apoya en un diálogo de respeto y libertad donde la toma de conciencia, como artista y ser humano, se convierte en raíz de su arte. Asumiendo de esta manera que la vanguardia resulta un ámbito de responsabilidad donde la poesía pone la palabra.

\section{Trascender la tradición}

La trayectoria musical de Enrique Morente invita a una profunda reflexión acerca de las significaciones que se esconden detrás de algunas palabras como pueden ser "tradicionalismo" y "tradición". De hecho, los argumentos, las posturas y las decisiones personales afloran conforme esa amalgama exclusiva de cante, música y poesía va sucediéndose y abren una escisión insoslayable entre los conceptos de tradición o tradicionalismo, los cuales, a su vez, mantuvieron en tensión el campo poético español de principios del siglo XX. Tal vez, podría asumirse el arte de Enrique Morente como una herencia del debate que, debido al neopopularismo, abordó una buena parte de

Revista de Investigación sobre Flamenco "La madrugá" 
(C) Servicio de Publicaciones de la Universidad de Murcia

http://revistas.um.es/flamenco

la Generación del 27. Sí a la tradición, pero asimilada desde el sentido de la responsabilidad que supone una actualización y desviada de las impurezas coloristas y estridentes del tradicionalismo. Así que el cantaor granadino coincide con esta reformulación moderna de la herencia artística, es decir, la comprensión especial de lo popular, del pasado y, por lo tanto, de la tradición del cante viene sostenida por un afán de depuración y estilización que se apoya en la imaginería simbólica de la mejor poesía.

Está en lo cierto Pedro G. Romero (2015c) cuando se refiere a la «vocación popular» que permea la obra de Morente y que establece sin duda una correspondencia con «su entendimiento del flamenco como un hecho social total» (ibidem). Esta comprensión del flamenco como un arte totalizador e indisociable de la realidad le condujo a preservar también su «corazón» y su «verdad» (Morente, cit. en Gutiérrez, 2006, p. 462). De fondo latía la intención de separarlo de las minorías y las doctrinas maniqueístas, su acto de universalizarlo pretendía convertirlo en un potente vehículo de comunicación, libre de manipulaciones. Explicaba Enrique Morente:

No se puede utilizar el cante como una bandera en nombre del pueblo, porque eso es mentir, engañar y entorpecer. El flamenco no se puede circunscribir a un momento histórico o a un tema social. Tan reaccionario es cantar flamenco de partido como sepultarlo en las peñas ortodoxas de la tradición (cit. en Gutiérrez, 2006, p. 462).

Precisamente, gracias a esta consciencia de la tradición, surge un espacio de plenitud en donde el conocimiento profundo le permite revolver sus raíces o impulsar su traducción ${ }^{1}$. Entonces no será una casualidad que el arte pictórico de Picasso y Goya le sirva de inspiración, pues alberga la libertad y la revolución que conlleva trascender una tradición que antes se ha dominado con total maestría y admiración.

El Morente de los primeros discos trasluce el esfuerzo por ahondar en la tradición del cante, por llegar hasta «los sonidos que no existen porque sólo están en el oído de quienes ya no viven» (Morente, cit. en Ariño, 2014, p. 20). Este propósito se extiende hasta la recuperación de Antonio Chacón, un referente indispensable en la Edad de Oro del cante flamenco y heredero del maestro Silverio Franconetti. Así que los hilos, que entretejen el pasado, se transforman en una posibilidad para meditar sobre el origen de la propia identidad. No se trata tan sólo de homenajear a Antonio Chacón en los primeros discos de juventud, sino de perpetuar y enlazar con una tradición verdadera para que no caiga en el olvido. En este sentido, el flamenco y la poesía comparten la misma predilección por salvaguardar la memoria, por ir en contra del olvido tomando la palabra. Enrique Morente lo sabía bien. Pero, como suele ocurrir en la juventud, el instinto es más fuerte que la sabiduría y ya el cantaor resaltaba que Antonio Chacón era «la encarnación del creador flamenco» (Morente, cit. en Mora, 2008, p. 56), casi como en una curiosa y soterrada declaración de intenciones.

Comprender la tradición significa indagar en las esencias, ir al tuétano de lo popular y restaurar un repertorio con respeto. Los dos primeros trabajos, Cante flamenco (1967) y Cantes antiguos del flamenco (1968) dan buena cuenta de esa labor personal donde los estilos tradicionales del cante se funden con la lírica anónima del acervo popular. De este modo, remitiendo a Menéndez Pidal (1948), la poesía contenida en el cante de sus dos primeros trabajos musicales es la que se «rehace en cada repetición», la que se «refunde en cada una de sus variantes» y la que permanece «más arraigada en la memoria de todos» (p. 76). Se hacía necesario convertir distintos y preciados retazos de la memoria en algo tangible y, por eso, rescató algunas composiciones

\footnotetext{
${ }^{1}$ Enrique Morente insistirá a lo largo de su trayectoria artística en que se «trata de traducir la tradición» (cit. en Ariño, 2014, p. 20). De hecho, «quería abrir un espacio de encuentro a la cultura, las artes, la poesía y la música» cuyo nombre sería «Casa de la Tradición y la Traducción» (ibidem).
} 
inéditas atribuidas a Enrique el Mellizo -"De tu querer apartarme" (soleares) y "Toíto me viene en contra" (seguiriya) en su primer disco, Cante Flamenco- y a Silverio Franconetti -"Los ojos abrió" (seguiriya), del segundo disco, Cantes antiguos del flamenco.

La pervivencia de la alianza entre la poesía popular y el flamenco se solidifica en estas primeras composiciones en las que se contemplan los rasgos definitorios de esta lírica flamenca: la desnudez, la franqueza y la sencillez. Las principales dualidades emocionales son de sobra conocidas: la vida y la muerte, el querer y el desengaño. En consecuencia, nos situamos ante cantes que producen un rotundo desgarro emocional y que han nacido desde el primer momento para ser cantados porque como apuntaría Demófilo en su segunda colección de Cantes flamencos: colección escogida (1887/2005): «una copla escrita, es una copla estropeada» (p. 418).

La voluntad de reconocerse en el espejo del pasado será fundamental para construir la imagen de futuro que desea proyectar Enrique Morente. Resulta revelador cómo la interpretación del «alma no adulterada, ni enmascarada» (Machado y Álvarez, 1887/2005, p. 418) de esta psicología poética y flamenca le conduce al descubrimiento de los autores cultos, Miguel Hernández y Antonio Machado, presentes en los discos venideros.

\section{Dominar la vanguardia}

El Enrique Morente inconformista surge con la eclosión de su tercer disco, Homenaje flamenco a Miguel Hernández (1971). Ahora cobra pleno sentido el concepto de traducción, insistiendo en él a lo largo de toda su trayectoria musical. Hay que hacerse preguntas: «¿Cómo traducir eso a un tiempo como el que vivimos?» (Morente, cit. en Gutiérrez, 2006, p. 99). Hay que dar con las respuestas. La interpretación escrupulosa de la tradición sentaba las bases para establecer el viraje hacia los juegos vanguardistas. Había que comprender a la perfección la pureza, pero también había que ser capaz de desmontar todas sus estructuras técnicas y estilísticas con el fin de otorgarle un significado distinto y una trascendencia nueva.

Ya en 1968 había aparecido un libro, El nacimiento de una contracultura, escrito por el profesor norteamericano, Theodore Roszak, cuyo subtítulo, "Reflexiones sobre la sociedad tecnocrática y su oposición juvenil", venía a ser una insinuación determinante de su contenido. El texto de Roszak no sólo movilizó intelectualmente a las generaciones de jóvenes a las que se dirigía sino que acuñó para siempre el controvertido término de Contracultura. Pero, ¿cómo definir la Contracultura? Roszak (1980) aludía a ella como «una exploración del comportamiento concreto de la conciencia» (p. 172) que se enderezaba hacia la crítica de todo ese «gran imperativo cultural» (p. 12) abarcado por la tecnocracia. En realidad, los jóvenes más avezados de las décadas de los sesenta y los setenta no iban sino en contra de los valores dominantes de la cultura que hoy denominaríamos como establishmentent. La Contracultura sí existió en España, pero atesoraba sus propias reservas. Jordi Costa en su libro, Cómo acabar con la Contra-Cultura. Una historia subterránea de España (2018), se refería a esa «revolución utópica» (p. 17), que más tarde fracasaría y sobre la que pesaba el fantasma de la Transición política. Se trataba de un tiempo entre la «sotana» y la «pana» (ibídem), donde el impasse, que había generado el tardofranquismo, provocó que «la piqueta rebelde socavara el viejo orden (tradicional y dictatorial) y abriese un horizonte de libertades» (Núñez Florencio, 2018).

Enrique Morente se convierte en un excelente intérprete de este período. Entiende que el flamenco no es un arte anquilosado, sino que está vivo y que, por este motivo, es sensible a las vicisitudes de su tiempo. Su gusto por lo «anti-auténtico» (Morente, cit. en Gutiérrez, 2006, p. 99), como él mismo lo definiría, revela, en realidad, la postura del artista genuino que forja sus lógicas estéticas e intelectuales en las reivindicaciones emprendidas por la poesía más excelsa. Esta postura íntima supone un salvavidas que le desliga y le ayuda a trascender las proclamas 
(C) Servicio de Publicaciones de la Universidad de Murcia

http://revistas.um.es/flamenco

socialmente fugaces de sus coetáneos.

Así que el cantaor acude a los círculos universitarios progresistas, lee a Miguel Hernández e incorpora su poesía en su cante. Lleva razón Steingress cuando conviene en señalar que el Nuevo Flamenco se conforma a partir de una subcultura que se aparta de los valores nacionalistas de la dictadura. Pero, en el caso de Enrique Morente, la etiqueta de "Nuevo Flamenco" tan sólo parece una excusa coyuntural que le sirve para iniciarse en el camino de su autoafirmación definido por su continuo deseo de experimentación más que por la ambición de fusionar distintos géneros musicales.

El artista granadino está trazando su propia evolución, dejando constancia de su intencionalidad: la recuperación del pasado constituye una forma de enfrentarse al futuro. La indagación en la tradición del cante ha dejado lecciones valiosas y ahora extenderá ese procedimiento en el abordaje de la poesía. Entonces discierne que la lectura de la tradición poética se convierte en un hecho de vanguardia cuando sirve para desacralizar la pulsión inmovilista del cante. La adaptación de Miguel Hernández, como en "Nanas de la cebolla" o "Sentado sobre los muertos", inicia un «diálogo cultural» (Vázquez Martín, 2011, p. 65) que tiñe de compromiso su obra musical. Aquí la poesía servirá de mediadora entre conceptos como pueblo y lucha, España y política y se situará en línea de igualdad con el cante. Aun salvando las distancias, entre Enrique Morente y Miguel Hernández se produjo un paralelismo artístico determinante, es decir, el compromiso se haría palmario cuando ambos ensamblaron el significado popular con la tradición culta de la poesía. Este hecho anunciaba que el joven maestro cantaor, que recibiría al año siguiente el Premio Nacional de Cante (1972), otorgado por la Cátedra de Flamencología, emprendía la apertura formal del universo flamenco que se había caracterizado hasta el momento por su cerrazón y «autorreferencialidad» (Vázquez Martín, 2011, p. 65). Pero lo más significativo era que esa apertura hacia las pretensiones de su contemporaneidad se llevaba a cabo a través de un poeta clásico y republicano. Se producía así una doble defensa de las libertades tanto a nivel artístico como cívico.

Por eso, aprovechando la presentación de Homenaje flamenco a Miguel Hernández, Juan Ibáñez (1971) escribía en la contraportada del disco: «Morente canta el cante. Morente no mata el cante. Lo busca, lo respeta y lo renueva. Lo mueve. El arte de Morente va al tiempo y viene del tiempo; fiel a sí mismo ha creado su estilo en la búsqueda de la pureza no del puritanismo. No es cantaor sirviente. Es artista» (p. 12). Esta fidelidad a uno mismo se materializó ya en el tercer disco. Se trataba de una apuesta musical y estética que, según declaraciones del propio Morente en 1985 lo «estimuló para hacer cosas distintas» (Velázquez Gaztelu, 2021, pp. 105-106) y que desvelaba además su afán de universalización. Explicaba Enrique Morente:

Para subsistir en el mundo de la flamencología de aquel momento, ese mundo que empezaba en las peñas flamencas, con ese concepto del cante que tenían, que todavía está bastante arraigado, debía tirar por otros caminos, cantar de otra manera, pensando en otros públicos que no entendían de flamenco pero que tenía que dirigirme a ellos: primero porque existía la posibilidad de cantarles lo que yo quisiera y podían darme dinero para vivir, y segundo, porque así me realizaba artísticamente, ya que iba con sinceridad y hacía tonos nuevos, formas nuevas, giros nuevos y metía letras nuevas (Velazquez Gaztelu, 2021, p. 106).

Esa «realización artística» abarca el deseo de ampliar sus públicos posibles. Se trataba de darle una vuelta de tuerca al sentido histórico que las vanguardias artísticas habían desarrollado,

\footnotetext{
${ }^{2}$ A José María Velázquez Gaztelu, que lo entrevistó en junio de 1985 para el programa Nuestro Flamenco de Radio Nacional de España (minuto 24). Ahora puede escucharse en línea dentro del Especial Enrique Morente (I) que RNE emitió en 2010. Recuperado de https://bit.ly/3DHclQI
} 
ahora no existía una ruptura con el pasado sino una reinterpretación conciliadora. Su cante que pretendía «promocionar valores nuevos, sin localismos, ni partidismos» (Morente, cit. en Almazán, 1970, p. 58), ya no era un «producto de productores destinado a productores», en palabras de Bourdieu (1993, p. 114) -para "connaiseseurs", como diría también el sociólogo francés en referencia a las prácticas vanguardistas- sino un hecho artístico que venía a desterrar todas las convenciones usando una multiplicidad de lenguajes universales. El ejercicio de asimilar el cante como una acción de vanguardia lo eleva a un estadio en el que ya deja de ser un mero arte representativo y se concibe como una abstracción donde confluyen las posibilidades del descubrimiento, el conocimiento y la mixtura. Su voluntad era la de alcanzar la máxima relativización pues no creía que hubiera «músicas aparte, ni arte aparte» (Morente, cit. en Ariño, 2014, p.13).

No obstante, la legitimación de su cante a través de referentes artísticos de primer orden lo protegerá de la efemeridad que rodeó a la cultura subterránea de la Transición española. A partir de Homenaje flamenco a Miguel Hernández, su discografía refleja un fenómeno complejo en el que se distingue un hibridismo entre tradición y renovación y en donde la poesía se transforma en un discurso capaz de conectar ambos polos. Como afirma Pérez Páez (2018):

No podemos establecer períodos cerrados en los que prime un proceder sobre el otro, ya que desde sus inicios es simultánea la práctica y reivindicación de la tradición con la actitud introspectiva y vanguardista; las formas tradicionales y las divergencias creativas con las que dar cauce y forma a su mundo interior se retroalimentan, preparando así un salto hacia el futuro que se impulsa en la tradición, que se nutre de su repertorio, formas y creadores, no sólo mediante la perpetuación de las formas sino también en su actitud, en su vitalidad. Morente hace simultáneo desde el inicio de su carrera el cante tradicional, su estudio e investigación, con el desarrollo de la expresión más personal de su propio mundo sonoro, construyendo un universo personal y variado a través de sus composiciones y una enorme diversidad de prácticas de hibridación de lo flamenco, de manera que sus propias ideas y composiciones se instalan entre lo ortodoxo y lo heterodoxo (p. 36).

Resulta muy acertada la apreciación de que su carrera musical no constituye una trayectoria de «períodos cerrados». De hecho, el retorno a la tradición se convierte en un signo de modernidad rebelde frente a la laxitud impuesta por las formas del flamenco posmoderno. Los siguientes discos representan una buena muestra de ese regreso a la tradición: Homenaje a don Antonio Chacón (1977), Essences Flamencas (1988), Morente-Sabicas, Nueva York-Granada (1990) y Morente flamenco (2009).

El interés de Morente por la revitalización de la tradición flamenca sostiene en el fondo una apuesta tan vanguardista como la llevada a cabo en la experimentación, pues ambos valores quedan expuestos a la misma apertura e intercambio intercultural. El cantaor no concibe un arte compartimentado con identidades estáticas, por eso, la inclusión de la poesía en el flamenco le ayuda a perfilar un campo estético donde todas las artes - cante, música, poesía y estéticaparticipan de una simbiosis positiva. Comprende que el futuro es otra forma de pasado en donde la poesía de convierte en un vehículo de comunicación entre esas dos realidades.

\section{La poesía, piedra de toque}

Enrique Morente confesaría que «quien escribe un poema lo hace por nada, casi nunca espera algo a cambio» (cit. en Gutiérrez, 2006, p. 630). La poesía para el cantaor es un arte desinteresado y generoso, capaz de establecer un diálogo con la vida, que considera imprescindible. La primera motivación, que sustentó la adaptación de la poesía culta para su cante, fue la escasez de letristas flamencos buenos. De alguna manera, intuye que los poemas, procedentes de la tradición culta, 
(C) Servicio de Publicaciones de la Universidad de Murcia

http://revistas.um.es/flamenco

propician la posibilidad de ofrecer al cante una subjetividad más profunda y atemporal. Las categorías inherentes a cualquier obra artística, como su belleza o su sentido particulares, no son lineales, ni están restringidas a su género, sino que pueden confluir hacia las demás artes y será esa teoría personal la que transvase al flamenco. Explica:

Hay de flamenco lo que se quiera, es decir, un artista hace un poema, escribe una obra y esa obra debe de servir para que cualquier otro artista de cualquier otro género del mundo pueda utilizarla como inspiración y servirse de ella para que pueda continuar el carro (Morente, cit. en Gutiérrez, 2006, p. 633).

La meditación aparece como la otra cara de la moneda de la intuición. Enrique Morente selecciona con cuidado sus poetas, una elección meticulosa que había aprendido de Pepe de la Matrona, «un maestro en el tema de las coplas». Y es que las conversaciones con él siempre giraban en torno a las letras: «Eso me ha marcado mucho, afortunadamente, y de ahí he pasado mi afición a la poesía culta. Yo conocí antes la letra del cante al preocuparme y haberme dedicado pasionalmente mucho tiempo a eso» (Morente, cit. en Gutiérrez, 2006, p. 635). No obstante, serán los mecanismos de la propia poesía culta los que ayuden a perfilar su poiesis musical. En palabras de Romero (2015a):

Morente construye sus herramientas, los instrumentos de su poiesis, operando con la esthesis, asumiendo formas de cantar, escuelas diferentes y heterodoxas para el canon de su tiempo, escuchando, abriéndose a otras músicas, a formas «degeneradas» de flamenco, desde Caño Roto hasta Emilio el Moro, a otras músicas populares -tango, son, rock and roll-, a la música culta, a las polifonías, a la esencia de la música religiosa, incluyendo las expresiones más vanguardistas y radicales como Luigi Nono o Helmut Lachemann. Es desde esa práctica abierta que va configurando una forma diferente de acudir al flamenco. Pero indudablemente hay elementos de estructuración, de proyecto. No se trata sólo de unas determinadas formas, de defender ciertas estéticas frente a otras, más bien de encontrar un procedimiento más veraz, más ajustado a lo que el propio flamenco ha desenvuelto. Lo hace además subrayando el carácter performativo de este arte, haciendo del mismo el sistema de conocimiento.

La poesía viene a apoyar este «sistema de conocimiento», este «montaje» en el que la «palabra» y el «canto» deben conjugarse como una impecable «unidad estética». Más allá de la adaptación de poemas cultos y letras populares, buscó y persiguió naturalizar el vínculo entre verso y música. Prosigue Romero (2015c):

San Juan de la Cruz, por supuesto, prácticamente lo ha reinventado Morente -todavía recuerdo una Semana Santa en Granada donde un grupo de gitanillos porfiaban que "Aunque es de noche" se ha cantado desde siempre en la noche sacra granadina. Nadie ha cantado así a Miguel Hernández o a Antonio Machado. También a Bergamín o Pedro Garfias les ha dado una dimensión inusitada. Y con Lorca no digamos, no se ha limitado a sus poemas, Morente hace suyas las letras, fragmentos que monta aquí o allá, en tangos o bulerías, naturalizándolos ya flamencos. Es habitual, de hecho, ver estos fragmentos naturalizados ya en otras voces, tomando las letras la entonación precisa de Morente. No digamos el Rafael Alberti de "Si mi voz muriera en tierra" que se ha incorporado de pleno a las alegrías de Cádiz. Morente era muy consciente de esa herramienta.

El cantaor ha adaptado un total de cuarenta poetas cultos de nacionalidades y momentos históricos dispares, pero, salvo contadas excepciones, todos estos autores están ligados por la admiración que profesaron a la palabra sencilla que surgía de la voz popular. No debemos olvidar que Homenaje flamenco a Miguel Hernández supone un punto de inflexión en su trayectoria musical, pues ahí nace el «el compositor, un creador que ya no es sólo el intérprete de un repertorio tradicional preestablecido» (Páez, 2018, p. 25). 
Resulta significativo que Morente acudiese a Antonio Machado tras su experiencia con Miguel Hernández. Ya el título del quinto disco de estudio refleja una clara adscripción machadiana, $S e$ hace camino al andar (1975). Dicho título se extrae de forma íntegra de un verso que compone el poema XXIX de Proverbios y Cantares (1917). Por aquellas fechas, el poeta-caminante iba acoplando su voz a la del poeta popular, apoyado en el «folklore metafísico de la región andaluza». Por eso, no extraña que considerase la copla como «un documento sincero del alma española» (Machado, 1988, p. 2052). De alguna manera, Morente se adhiere a esa metáfora del camino emprendida por Machado, pero él la reformula como el viaje particular que acaba de dar comienzo, incluyendo palos de creación personal en su disco.

Sin embargo, será en Despegando (1977) donde Morente abrace la adaptación del poema "Yo escucho los cantos", perteneciente a Soledades (1907). La bulería de título homónimo materializa muy bien la emoción flamenca que a Antonio Machado le interesaba plasmar para componer su primer libro de poemas, quien sabía que en lo más recóndito del cante andaluz descansaba «no solamente un drama íntimo, sino un drama colectivo» (Predmore, 1989, p. 63).

También Manuel Machado había manifestado su admiración por la copla andaluza. Cante hondo (1912) significó la recopilación de todos sus cantares escritos hasta la fecha, cuyas coplas estaban hechas «más de gritos que de palabras» (Machado, 1912/2008, p. 11). Si en un principio el libro se había concebido para la disposición del «provecto Juan Breva», el «insuperable Chacón» o la «celebérrima Antequerana», según revelaba su propio autor en el prólogo, sería Enrique Morente el que recogería una versión de su cantar "La pena" para el disco Sacromonte (1982).

La lectura de Antonio Machado establece una transición coherente que conduce al cantaor hacia el descubrimiento de otros poetas. En primer lugar, la emoción cordial, que recorría su poesía, le ayudaba a Enrique Morente a desligarse de la agitación cívica que había experimentado con Miguel Hernández, en segundo lugar, la metafísica impregnada en su conciencia poética sería un buen vehículo para descubrir los místicos del Siglo de Oro, Fray Luis de León, San Juan de la Cruz o Santa Teresa de Jesús, y, en tercer lugar, su lírica simbolista y neorromántica le conectaba con las pretensiones estéticas de los autores de la Generación del 27 que más le interesaban al cantaor, Federico García Lorca y Rafael Alberti.

Cruz y luna aparecería en 1983 e incorporaba un poema de San Juan de la Cruz y otro del poeta andalusí, Muhámmad al-Mutámid. El disco llevaba impresa una melancolía oscura y plácida con reminiscencias sonoras ligeramente arábigas. El tango personal "Aunque es de noche" suavizaba la tensión mística original del poema sobre el que se componía, "Cantar del alma que se goza de conocer a Dios por fe". Los versos de San Juan de la Cruz sugieren una naturalización y un alcance más populares a través de la voz de Morente. Una fortuna similar correría el poema "Amor onírico" de Muhámmad al-Mutamid, que el cantaor adapta con libertad, pero sin alterar su sensualidad inicial en la canción "En un sueño viniste".

El cantaor volvería a traducir la voz de San Juan de la Cruz en Misa flamenca (1991), ésta en vez en el "Credo". Por otro lado, el "Gloria" y el "Sanctus", pertenecientes al mismo álbum, descansaban sobre composiciones de Fray Luis de León. El primero versionaba "Oración", que Fray Luis de León había escrito a imitación del cardenal Pietro del Bembo, mientras que las soleares del "Sanctus" recogían su "Oda a la Ascensión". Contrariamente a lo que podía pensarse, la emoción de la poesía mística tenía mucho que ver con la emoción jonda, pues ambas se afanaban en la comunicación de lo inefable. La sabiduría mística constituía además una metáfora de la creación morentiana que se apoyaba en la tensión justa entre intelecto, sentimiento y humanidad.

Un año antes, en 1990, el cantaor había publicado Enrique Morente: en la Casa-Museo de Federico García Lorca, inaugurando su célebre alianza con la obra del poeta granadino, que llegaría a consumarse con Omega (1996), Morente-Lorca (1998) y Llanto por Ignacio Sánchez Mejías (2010). No es una casualidad que el Lorca que más interesa a Morente sea el que entre en 
(C) Servicio de Publicaciones de la Universidad de Murcia http://revistas.um.es/flamenco

contacto con el surrealismo. De hecho, sus adaptaciones de la obra teatral, Así que pasen cinco año (1931), y de los poemarios Poema del cante jondo (1921) y Poeta en Nueva York (1930) lo corroboran.

La interpretación de la vanguardia realizada por Morente guardaba su parentesco con la lorquiana. La tradición había resultado para ambos un espacio en el que podían hundir las raíces de la experimentación al mismo tiempo que establecían un interesante diálogo de ida y vuelta entre lo imperecedero y la novedad. A su vez, la vanguardia, con sus mecanismos, les permitía cuestionar todas las convenciones que la tradición pudiese albergar. A Morente le atrae el surrealismo lorquiano por todo lo que contenía de «quiebra» y de «mezcla», por ser «inconsciente» e «instinto» en una misma expresión (Fuentes, 2004, p. 216). Y el duende del flamenco, que también participa de esta lógica de la libertad, viene a canalizar esa sensibilidad.

El cantaor granadino se convierte en un altísimo traductor de la trinidad sobre la que se fundó la obra lorquiana: tradición, vanguardia y duende, heredando, asimismo, toda una mitología del Sur neorromántica y simbólica. Entonces, la poesía de García Lorca hecha cante se transforma en una declaración de principios personales: defensa del enigma en detrimento del tópico, permanencia de la pureza de lo popular y humanización de la vanguardia.

Más allá de la innovación musical que supuso Omega (1996), Enrique Morente supo reconocer la esencia de Poeta en Nueva York, es decir, «la del poeta que sueña y la de la ciudad sin sueño» (Menarini, 1996, p. 30) y la transcribe a su propio dilema: la del cantaor que sueña y la de la sociedad sin sueño vencida por la globalización capitalista. Por eso, no sorprende, que los poemas de García Lorca se alternen con las reivindicaciones de Leonard Cohen: «Me condenaron a 20 años de hastío/ por intentar cambiar el sistema desde dentro [...] Primero, conquistaremos Manhattan/ después, conquistaremos Berlín»(de la canción "Manhattan").

Otro poeta de la Generación del 27, que Morente recuperó con lucidez, fue Rafael Alberti. Pero la argucia consistió en situarlo al lado del poeta cubano Nicolás Guillén. Tal habilidad dio como resultado el disco Negra si tú supieras (1992), que no sólo quedó impregnado por la melancolía luminosa que encerraba el paraíso perdido de Marinero en tierra (1924) sino que ésta sirvió de enlace transoceánico con los poemas negristas de Nicolás Guillén. Se produjo así una reinterpretación evocadora de los cantes de ida y vuelta a través de las adaptaciones de "Si mi voz muriera en tierra", de Rafael Alberti, y de los poemas de Nicolás Guillén.

Tal vez merezca una mención aparte el binomio, Enrique Morente - Pablo Picasso, cristalizado en diferentes álbumes: Morente: Canto y cante a Picasso (2003), Pablo de Málaga (2008) y El barbero de Picasso (2011). De cualquier modo, el pintor universal se había atrevido a afirmar que «si yo fuera chino, no sería pintor sino escritor. Escribiría mis pinturas»3 Picasso se desdobla en una poesía que es «autofágica», que «es alimentaria, se alimenta a sí misma de sí misma y alimenta su imaginario con las asociaciones libres más inesperadas» (González Ángel, 2020, pp. 131-132). Esta peculiaridad es captada por el cantaor que la aclimata a su condición de andaluz universal.

Morente siente por Picasso una fijación similar a la que le suscita García Lorca, descubre y ahonda en su escritura poética, prácticamente aún desconocida, y detecta una compatibilidad significativa. Como el propio Pablo Picasso expresó: «Al fin y al cabo, todas las artes son una sola. Se puede escribir una pintura con palabras, como se pueden pintar sensaciones en un poema $>4$ Curiosamente, García Lorca (2008) también había sentenciado que «todas las artes son capaces de duende» (p. 333). De este modo, el cantaor converge en esta visión de una obra de arte integral

\footnotetext{
${ }^{3}$ La cita aparece recogida en la presentación web dedicada a la exposición "Picasso poeta", que tuvo lugar del 8-11-2019 al 1-3-2020 en el Museu Picasso de Barcelona. Recuperado de https://bit.ly/334Xrqx.

${ }^{4}$ Ibidem.
} 
y transmite con una sabiduría audaz esta cosmovisión artística heredada. Y, al igual que ocurría con García Lorca, las formas líricas en las que Pablo Picasso asume el surrealismo, también estimulan a Morente.

Hay que recurrir a Octavio Paz y a su libro Las peras del olmo (1957/1984), para hallar una definición del surrealismo verdaderamente ajustada a las pretensiones artísticas de García Lorca, Pablo Picasso y Enrique Morente, en donde se sostiene que el surrealismo venía a «poner en entredicho a lo que hasta ahora ha sido considerado inmutable por nuestra sociedad, tanto como una desesperada tentativa por encontrar la vía de salida» (p. 137). Por lo tanto, será en esta faceta de metamorfosis y contradicción en la que coincidan los tres artistas.

Pablo de Málaga presentaba la misma innovación revolucionaria que Omega. Ahora los elementos electrónicos habían sustituido al rock y los poemas de Picasso sustentaban el mismo carácter vanguardista. La creación del disco encontraba su germen en otra pequeña compilación anterior, Morente: Canto y cante a Picasso (2003), que el cantaor había realizado con motivo de la apertura del Museo Picasso de Málaga en ese año. Pablo de Málaga profundiza en los textos de Picasso produciendo resultados tan geniales como "Guern-Irak", "Adiós, Málaga" o "Autorretrato", que venía introducida por la misma voz de Picasso. Además hay que señalar la correspondencia entre "Guern-Irak" y "Manhattan", de Omega, pues ambas canciones contenían ese deseo de "poner en entredicho» la barbarie de la sociedad, pero esta vez tomando como referencia el Guernika de Picasso con el objetivo de denunciar la Guerra de Irak.

Quizás, cerrando un círculo infinito, Enrique Morente sellaba su testamento discográfico con dos álbumes dedicados a las figuras con las que más se había emparentado su vanguardismo: Federico García Lorca, presente de nuevo en Llanto por Ignacio Sánchez Megía (2010) y Pablo Picasso, ahora en El barbero de Picasso (2011).

\section{Conclusiones}

Enrique Morente se escapa de las interpretaciones definitivas y concluyentes. Su estrecho vínculo con la poesía de carácter culto le condujo a un territorio artístico e intelectual en donde los argumentos teóricos invalidan sus viejas perspectivas y requieren por lo tanto nuevos sentidos. Subyace a lo largo de toda su trayectoria musical una apuesta humana por los valores heredados del surrealismo comprendido más allá de su vanguardia y puesto en conexión con su dimensión epistemológica. Así la relación entre su cante y la poesía se atiene al código de la simbiosis y precisa de una traducción. De hecho, fue el concepto de traducción el que vertebró sus constantes diálogos entre las distintas disciplinas artísticas. Traducir la tradición para la vanguardia. Traducir la vanguardia para la tradición. De este modo, no surgen las posiciones antitéticas, tan sólo el entendimiento dispuesto como un terreno fértil para la propia superación.

Estas consideraciones son importantes para entender el arte de Enrique Morente. Motivado por superar el lastre de la simbología del repertorio decimonónico de las letras flamencas, el cantaor se convierte en el fundador de una nueva estética flamenca capaz de conciliar tradición y vanguardia por medio de una lectura intelectualizada de la poesía culta. Así la lectura se transforma en un acto de apertura y concibe el flamenco como un campo de posibilidades.

La predilección por el poeta García Lorca y por el pintor Pablo Picasso sostienen esta mirada y enlaza con sus propias exigencias como artista. La libertad resulta entonces de un proceso de meditación y consenso. Con Enrique Morente, el cante flamenco adquiere la categoría de ser una expresión artística interdisciplinar donde la universalización se alza como premisa básica. Sin embargo, la continua adaptación de ese nutrido conjunto de poetas cultos para sus propias letras carecería de sentido sino la hubiese emprendido desde el cuestionamiento de la propia identidad como artista y a su vez de los límites estructurales del flamenco. Enrique Morente no obviaba 
(C) Servicio de Publicaciones de la Universidad de Murcia

http://revistas.um.es/flamenco

que cualquier indagación sobre la propia identidad y sobre la unidad de lo establecido conllevaba un peligro e incluso un falseamiento, pero el rigor de la honestidad salvó su arte de la frustración y el orgullo.

\section{Bibliografía}

ARIÑo, Amaranta (Ed.) (2014). Universo Morente: creación y vida de Enrique Morente. Granada: Patronato de la Alhambra y el Generalife.

Almazán Marcos, Francisco (1970). Enrique Morente. Triunfo. Año XXV, n. ${ }^{\circ} 443$ (28 de noviembre), pp. 58-59.

Bordieu, Pierre (1993). The field of Cultural Production. Essays on Art and Literature. Great Britain: Columbia University Press.

Costa, Jordi (2018). Cómo acabar con la Contra-Cultura: una historia subterránea de España. Madrid: Taurus.

Fuentes, Ivette (2004). El Surrealismo en Federico García Lorca: las voces de un duende. Moenia: Revista lucense de lingüística y literatura, n. ${ }^{\mathrm{o}}$ 10, pp. 213-224.

García Lorca, Federico (1996). Poeta en Nueva York (edición de Piero Menarini). Madrid: Espasa Calpe.

García Lorca, Federico (2008). Obras completas (edición de Miguel García Posada). Madrid: Akal.

GonzÁlez Ángel, Sara (2020). El siglo de Oro español en el imaginario surrealista: la poesía de Pablo Picasso (tesis doctoral). Sevilla: Universidad de Sevilla.

GutiérRez, Balbino (2006). Enrique Morente, la voz libre. Madrid: Edición Fundación Autor.

IBÁÑEz, Juan (1971). Homenaje flamenco a Miguel Hernández (estuche del disco). Hispavox. Recuperado de https://cutt.ly/sTCrJHy.

Machado y Álvarez, Antonio (1887/2005). Obras completas (edición, introducción y notas de Enrique Baltanás). Sevilla: Diputación Provincial de Sevilla, Área de Cultura y Ecología.

Machado, Antonio (1988). Poesía y prosa (edición crítica de Oreste Macri con la colaboración de Gaetano Chiappini). Madrid: Espasa-Calpe.

Machado, Manuel (1912/2008). Cante hondo: cantares, canciones y coplas compuestas al estilo popular de Andalucía (tomo IV) (postfacio de Domingo Rodríguez Romero). Barcelona: Nortesur.

Menéndez Pidal, Ramón (1948). Los romances de América y otros estudios. Buenos Aires (Argentina): Espasa Calpe.

MorA, Miguel (2008). La voz de los flamencos: retratos y autorretratos. Madrid: Ediciones Siruela.

NúÑez Florencio, Rafael (2018). Cómo acabar con la Contracultura: una historia subterránea de España. El Cultural (14 de septiembre). Recuperado de https://cutt.ly/ATCAE7y.

PAZ, Octavio (1957/1984). Las peras del olmo. Barcelona: Seix Barral.

PÉREz PÁEz, Julián (2018). Enrique Morente: de la revalorización del cante (1963-70) a la renovación del flamenco (1970-2010). Sinfonía virtual: Revista de música clásica y reflexión musical, n. ${ }^{\circ} 34$, pp. 1-108. Recuperado de https://cutt.ly/uTCPuTe.

Predmore, Michael P. (1989). La herencia andaluza en las Soledades de Antonio Machado. Ínsula: Revista de Letras y Ciencias Humanas, n. 506-507, pp. 61-64.

Romero, Pedro G. (2015a). El don de Enrique (I). Recuperado de: https://cutt.ly/1TCotxa.

Romero, Pedro G. (2015b). El don de Enrique (II). Recuperado de: https://cutt.ly/oTCoi7i.

Romero, Pedro G. (2015c). El don de Enrique (III). Recuperado de: https://cutt.ly/0TCossf. 
Revista de Investigación sobre Flamenco "La madrugá"

Roszak, Theodore (1980). El nacimiento de una contracultura. Barcelona: Kairós.

VÁzquez Martín, Eduardo (2011). Enrique Morente: la voz del Albaicín y los poetas. Letras libres, n. ${ }^{\circ}$ 113, pp. 65-65. Recuperado de https://cutt.ly/LTCPbH2.

Velázquez Gaztelu, José María (2021). De la noche a la mañana: medio siglo en la voz de los flamencos. Sevilla: Athenaica. 